\title{
RAND
}

\section{Why Did the Welfare Rolls Fall During the 1990s? The Importance of Entry}

Jeffrey Grogger, Steven J. Haider, and Jacob Klerman

DRU-3004

March 2003

\section{Labor and Population Program Working Paper Series 03-07}

The RAND unrestricted draft series is intended to transmit preliminary results of RAND research. Unrestricted drafts have not been formally reviewed or edited. The views and conclusions expressed are tentative. A draft should not be cited or quoted without permission of the author, unless the preface grants such permission. 



\section{Why Did the Welfare Rolls Fall during the 1990s? The Importance of Entry* Jeffrey Grogger, Steven J. Haider, and Jacob Klerman}

Forthcoming in the American Economic Review, May 2003

During the late 1990s, the welfare caseload fell precipitously. Whereas 5 million families received cash welfare in 1994, only 2.1 million families received aid in 2000. As a fraction of the U.S. population, this represents the lowest level of welfare receipt since 1964 (U.S. Department of Health and Human Services, 2002).

The decline in the caseload could have resulted from a decrease in entries, an increase in exits, or some combination of the two. Although a number of studies have analyzed welfare exits, either implicitly or explicitly, few have focused on welfare entries.

Yet entries may be important for a number of reasons. Conservative proponents of welfare reform explicitly sought to reduce welfare entries, particularly entries related to unwed childbearing (see R. Kent Weaver, 2000, ch. 6 ). Such observers might question the success of welfare reform if the decline in the caseload resulted entirely from increased exits.

Entry effects may also have implications for the provision of in-kind transfers. Historically, both Food Stamps and Medicaid were closely linked to welfare: families typically applied for welfare and Food Stamps at the same time, and Medicaid insurance for families was limited to families on welfare. If families primarily learn about non-cash transfer programs when they first apply for welfare, then policy interventions that reduce welfare entry could also reduce take-up of such safety net services.

Finally, entry effects may affect one's interpretation of recent research on welfare reform. Studies that track families as they move off the welfare rolls (so-called "leaver" studies) shed light on the behavior and well-being of families exiting welfare. However, if recent policy 
changes have had important effects on welfare entries, then such studies provide only a partial portrayal of how those changes have affected life in the low end of the income distribution.

Our objective in this paper is to provide some evidence on the importance of welfare entries. To do this we analyze both nationwide survey data from the Survey of Income and Program Participation (SIPP) and administrative data from California's Medi-Cal Eligibility Determination System (MEDS).

\section{The Data}

The SIPP consists of a number of panels, each of which is a longitudinal probability sample of the U.S. population. We include data from 1986 through 1999.

Panel questionnaires are administered at four-month intervals, providing multiple waves of data for each respondent. At each wave, the SIPP asks respondents about their welfare receipt in each of the previous four months. Although these data could be used to construct monthly welfare-use records, they suffer from "seam bias," meaning that reported transitions are much more likely to occur between waves rather than within waves (Rebecca M. Blank and Patricia Ruggles, 1996). For this reason, we only make use of data from month 4 of each wave.

The sample consists of women between the ages of 15 and 54 who were present at the first wave of the panel. A respondent enters welfare in wave $t$ if she was not receiving aid at wave $t-1$ but received aid at wave $t$. She exits if she received welfare in wave $t-1$ but not in wave $t$. Participation rates at wave $t$ are calculated as the number of persons on aid at wave $t$ divided by the number of persons in the sample.

The MEDS provides a longitudinal monthly roster of all welfare recipients in California. We draw a 3-percent random sample for our analysis. The resulting file contains 282,381 people and $10,966,420$ person-months during the interval 1989 to $2000 .^{1}$ 
Welfare exits can be observed directly in the file. The estimation of entry rates requires a denominator of the population at risk, for which we rely on the Intercensal Population estimates generated by the United States Census Bureau. These data provide annual population estimates; we use linear interpolation to obtain monthly estimates.

\section{Results}

Figures 1 and 2 plot trends in welfare entry, exit, and participation rates in the SIPP and the MEDS, respectively. In each figure, the circles represent actual data. ${ }^{2}$ The solid lines in Panels A and B represent lowess smooths of the actual transition rates. The smoothing parameters are chosen to generate simulated participation rates that best fit the actual participation data shown in Panel C. The simulated participation rates, represented by the solid lines in Panel C, are calculated using the transition rule:

$s_{t}=\left(1-x_{t}\right) s_{t-1}+e_{t}\left(1-s_{t-1}\right)$

where $s_{t}$ denotes the simulated participation rate, $e_{t}$ denotes the smoothed entry rate, and $x_{t}$ denotes the smoothed exit rate.

Means of each of the series in Figures 1 and 2 are presented along the $y$-axes. Entry rates are much lower in the SIPP than in the MEDS, although exit rates are similar. Participation rates are higher in the MEDS, the result of the higher entry rates.

Panels A and B of Figures 1 and 2 show that, in both the SIPP and the MEDS, the entry rate decreased sharply after 1994 . The decline may have started as early as 1991 in California. Between 1994 and the end of the sample period, the entry rate (computed from the smoothed data) fell by 45 percent in the SIPP and by 52 percent in the MEDS.

At the same time, exit rates were rising. The increase was greater in the SIPP than in the MEDS. Between 1994 and the end of the sample, exit rates rose by 104 percent in the SIPP and 
69 percent in the MEDS.

From these figures, it is clear that falling entry contributed to the decline in welfare participation rates. To illustrate their importance, we carry out some counterfactual simulations. In one set of simulations, we depict the importance of entry by using equation (1) to simulate participation rates, holding exit rates after the caseload peak fixed at their values at the time of the caseload peak (January 1994 in the SIPP; January 1995 in the MEDS). In the other, we depict the importance of exit by holding entry rates fixed.

These counterfactual simulations are plotted along with the baseline simulations (from Panel $\mathrm{C}$ of Figures 1 and 2) in Figure 3. The dotted lines reveal the importance of entries; the dashed lines reveal the importance of exits. Declining entry rates played important roles in both data sets. In California, declining entries were actually more important than rising exits.

Table 1 quantifies the importance of entry and exit. Column (1) shows the peak participation rate and column (2) shows the decline from the peak to the end of the sample period. Both of these sets of figures are based on the baseline simulations presented in Figure 3. Columns (3) and (4) show the decline in the participation rate due to entry, in absolute and relative terms. These are based on the endpoints of the fixed-exit counterfactuals represented by the dotted lines in Figure 3. Columns (5) and (6) show the absolute and relative declines due to exit, based on the fixed-entry counterfactuals represented by the dashed lines.

In both cases, the components of change due to entry and exit add up to "explain" about 110 percent of the actual change. This is not surprising. Due to the non-linearity of equation (1), there is no reason to expect the components to add up to 100 percent.

Both sets of decompositions show that declining entry rates played an important role in explaining the decline in welfare participation. In the nationwide SIPP data, entry explains 
nearly 40 percent of the decline. In California, where exit rates rose less rapidly than in the nation as a whole, entry was even more important. Falling entry rates account for over 60 percent of the decline in welfare participation in the MEDS.

\section{Conclusions}

Both nationwide survey data and administrative data from the state with the largest welfare caseload indicate that the decline in welfare participation rates had much to do with decreasing entry. In both data sets, entry explained roughly half of the decline in the caseload. As we noted in the Introduction, this finding has implications for interpreting the success of welfare reform and for the take-up of safety net services. It also has important implications regarding research on welfare-related behavior.

A recent survey of the literature revealed 32 experimental studies that attempted to assess the effects of welfare reform, all but one of which were based on families receiving or applying for welfare (Grogger, Lynn Karoly, and Klerman, 2002). Such experiments reveal largely how reform affects exits and other aspects of behavior among families at risk of exit. In light of our results, this suggests an imbalance in the nation's research agenda. Social experiments are costly, yet they provide no information about half the families responsible for the declining caseload — namely those who did not apply for welfare. ${ }^{3}$ Although a few recent nonexperimental studies have focused on entries, suggesting that they have been influenced by the economy and by recent expansions in the Earned Income Tax Credit (Kerman and Haider, 2002; Grogger, 2002), more research on this important topic is clearly warranted. 


\section{References}

Blank, Rebecca M., and Patricia Ruggles, "When Do Women Use AFDC and Food

Stamps? The Dynamics of Eligibility versus Participation.” Journal of Human

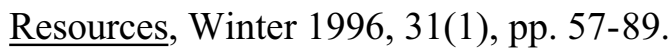

Grogger, Jeffrey. " Welfare Transitions in the 1990s: The Economy, Welfare Policy, and the EITC." Mimeo, UCLA, December 2002.

Grogger, Jeffrey, Lynn Karoly, and Jacob Klerman. Consequences of Welfare Reform:

A Research Synthesis. Santa Monica, CA: RAND. 2002.

(http://www.acf.hhs.gov/programs/opre/welfare_reform/reform_cover.html)

Haider, Steven J. and Jacob A. Klerman. "Dynamic Properties of the Welfare Caseload." Mimeo, RAND, July 2002.

Hoynes, Hilary Williamson, 'Local Labor Markets and Welfare Spells: Do Demand Conditions Matter?" Review of Economics and Statistics, August 2000, 82(3), pp. 351 368.

Klerman, Jacob A., and Steven J. Haider. “A Stock-Flow Analysis of the Welfare

Caseload: Insights from California Economic Conditions.” Mimeo, RAND, September 2002.

U.S. Department of Health and Human Services. U.S. Welfare Caseloads Information. (http://www.acf.dhhs.gov/news/tables.htm)

Weaver, R. Kent. Ending Welfare as We Know It. Washington: Brookings Institution Press, 2000. 

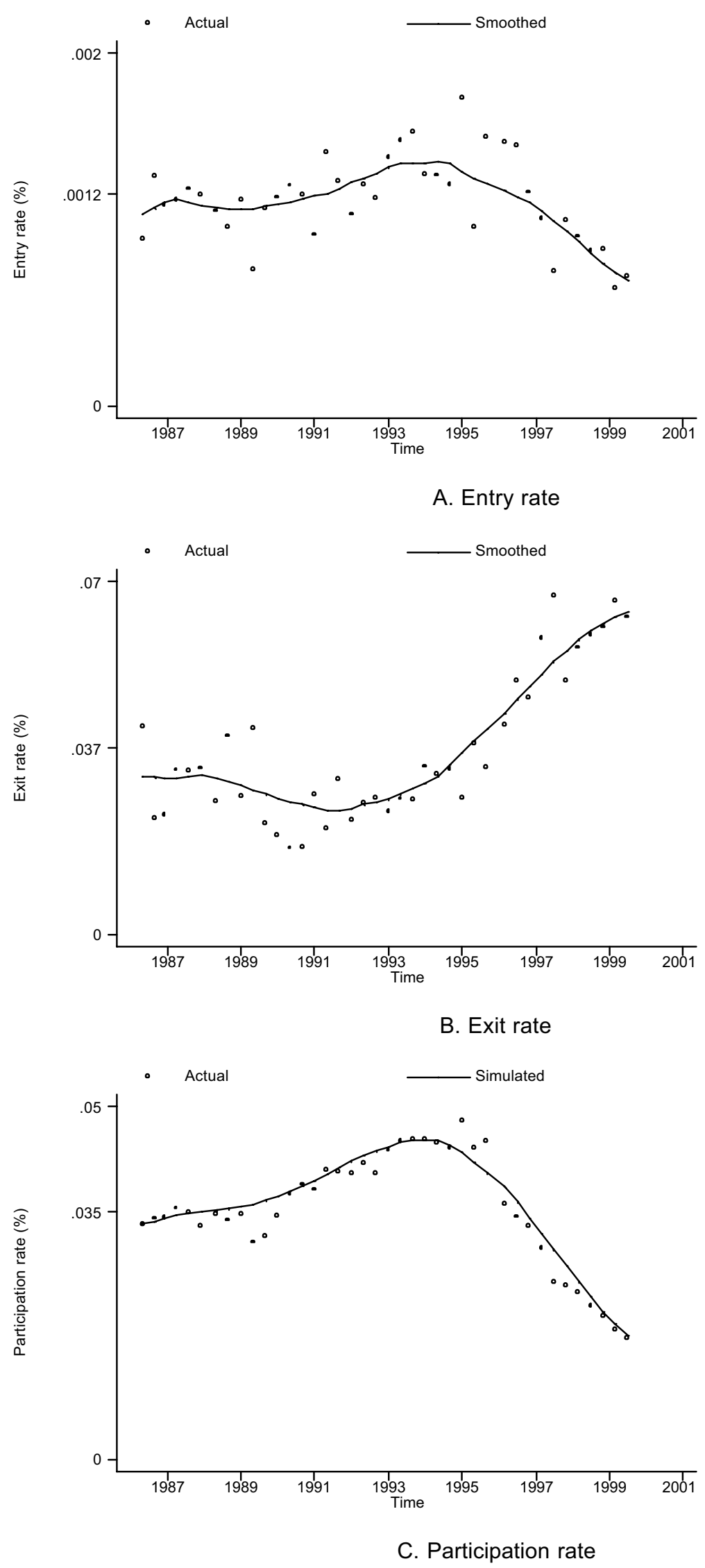

Figure 1: Welfare Transition and Participation Rates in the SIPP 

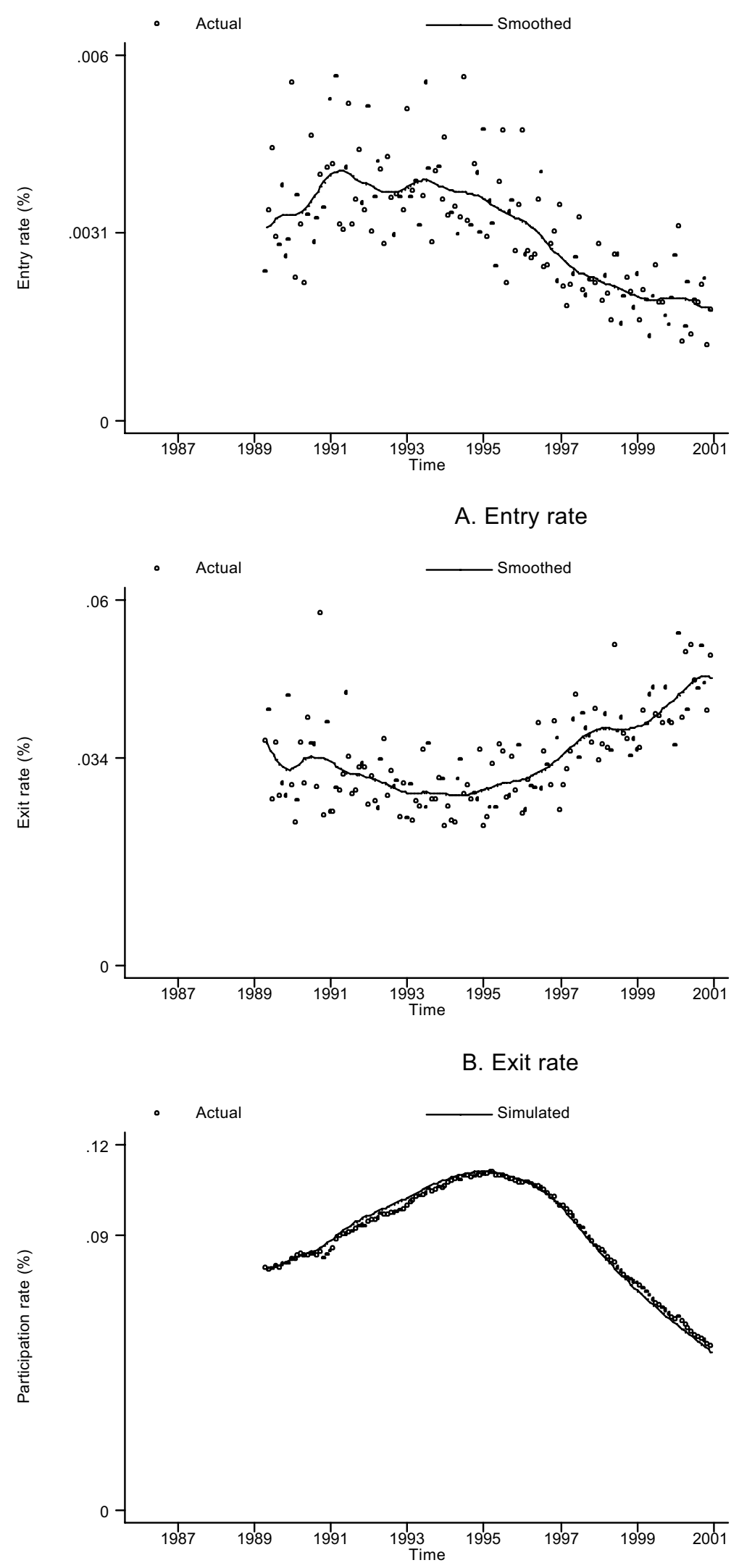

C. Participation rate

Figure 2: Welfare Transition and Participation Rates in the California MEDS Data 

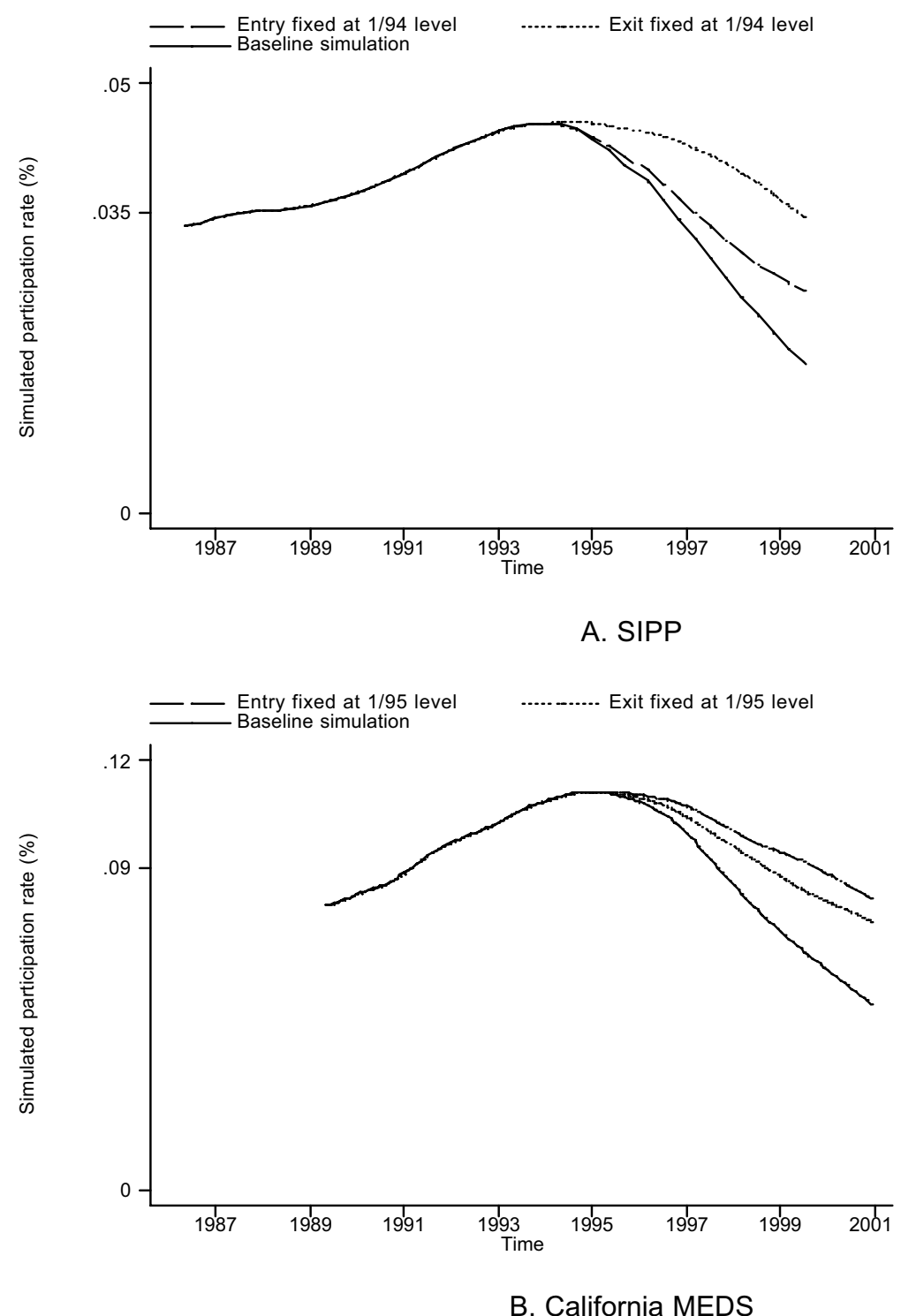

Figure 3: Baseline and Counterfactual Simulations 
Table 1

The Decline in the Welfare Participation Rate

\begin{tabular}{lcccccc}
\hline \hline & $\begin{array}{c}\text { Maximum } \\
\text { participation } \\
\text { Date }\end{array}$ & $\begin{array}{c}\text { Absolute } \\
\text { change }\end{array}$ & Absolute & Relative & Absolute & Relative \\
\hline SIPP & 0.045 & -0.028 & -0.011 & -0.392 & -0.019 & -0.696 \\
MEDS & 0.111 & -0.059 & -0.036 & -0.611 & -0.030 & -0.503 \\
\hline \hline
\end{tabular}




\section{Endnotes}

* University of California, Los Angeles and National Bureau of Economic Research; Michigan State University; and RAND. We thank James Ziliak for helpful comments. We gratefully acknowledge grant support from the Administration for Children and Families (ACF) and the Assistant Secretary for Planning and Evaluation (ASPE), U.S. Department of Health and Human Services (HHS). The opinions and conclusions herein are those of the authors, and do not necessarily represent the views of ACF, ASPE, HHS, or any other government agency. The authors thank Duncan MacRae and Elizabeth Roth for outstanding research assistance.

${ }^{1}$ Previous research indicates that there is considerable "churning" on and off welfare in the MEDS data. This churning is likely due to administrative record keeping rather than "real" entries and exits (see Hilary Hoynes, 2000). To mitigate such concerns, we recode one-month spells on and off of aid as not having occurred, following Hoynes (2000).

2 All SIPP-based estimates are based on weighted data. Triannual transition rates from the SIPP have been converted to monthly equivalents to ease comparison with the monthly transition rates from the MEDS.

3 If the decline in entry depicted above primarily represented a decline in re-entry rather than initial entry, then this would be an exaggeration, since welfare experiments at least implicitly capture re-entry as well as exit behavior. However, calculations from the MEDS indicate that, between January 1995 and the end of the sample period, reductions in initial entries were five times greater than reductions in re-entries. Relying on different decomposition techniques, Haider and Klerman (2002) also conclude that reentry is much less important than initial entry. 